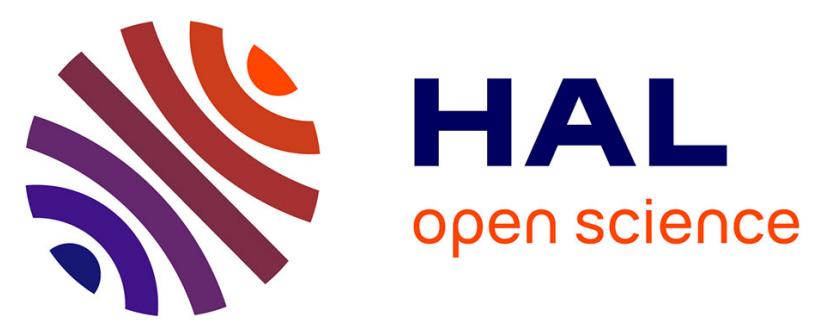

\title{
GaN/InGaN light emitting diodes with embedded photonic crystal obtained by lateral epitaxial overgrowth
} Aurélien David, B. Moran, K. Mcgroddy, E. Matioli, E.L. Hu, S. Denbaars, S. Nakamura, Claude Weisbuch

\section{- To cite this version:}

Aurélien David, B. Moran, K. Mcgroddy, E. Matioli, E.L. Hu, et al.. GaN/InGaN light emitting diodes with embedded photonic crystal obtained by lateral epitaxial overgrowth. Applied Physics Letters, 2008, 92 (11), pp.113514. 10.1063/1.2898513 . hal-00818814

HAL Id: hal-00818814

https://hal-iogs.archives-ouvertes.fr/hal-00818814

Submitted on 5 Apr 2016

HAL is a multi-disciplinary open access archive for the deposit and dissemination of scientific research documents, whether they are published or not. The documents may come from teaching and research institutions in France or abroad, or from public or private research centers.
L'archive ouverte pluridisciplinaire HAL, est destinée au dépôt et à la diffusion de documents scientifiques de niveau recherche, publiés ou non, émanant des établissements d'enseignement et de recherche français ou étrangers, des laboratoires publics ou privés. 


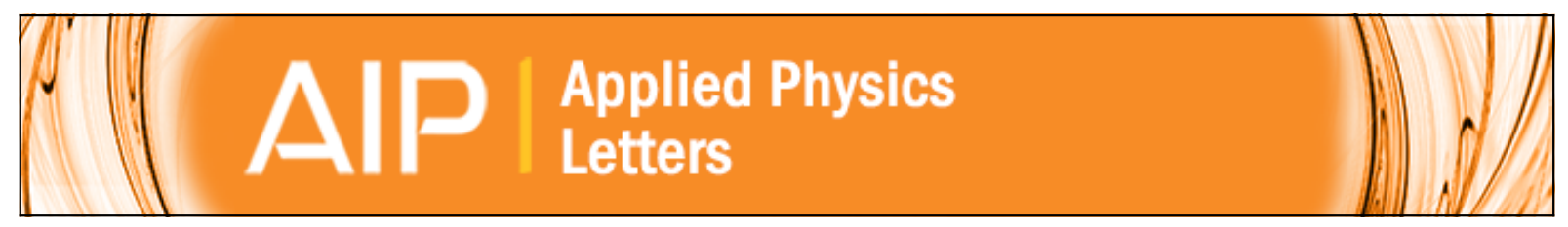

\section{Ga N/In Ga N light emitting diodes with embedded photonic crystal obtained by lateral epitaxial overgrowth}

Aurélien David, Brendan Moran, Kelly McGroddy, Elison Matioli, Evelyn L. Hu, Steven P. DenBaars, Shuji Nakamura, and Claude Weisbuch

Citation: Applied Physics Letters 92, 113514 (2008); doi: 10.1063/1.2898513

View online: http://dx.doi.org/10.1063/1.2898513

View Table of Contents: http://scitation.aip.org/content/aip/journal/apl/92/11?ver=pdfcov

Published by the AIP Publishing

\section{Articles you may be interested in}

InGaN/GaN tunnel junctions for hole injection in GaN light emitting diodes

Appl. Phys. Lett. 105, 141104 (2014); 10.1063/1.4897342

III-nitride light-emitting diode with embedded photonic crystals

Appl. Phys. Lett. 102, 181117 (2013); 10.1063/1.4804678

Lateral current injection photonic crystal membrane light emitting diodes

J. Vac. Sci. Technol. B 28, 359 (2010); 10.1116/1.3360891

Enhanced light extraction in nitride light-emitting diodes by epitaxially grown photonic-crystal nanopyramid arrays Appl. Phys. Lett. 95, 123120 (2009); 10.1063/1.3236784

Enhanced emission efficiency of Ga N/In Ga N multiple quantum well light-emitting diode with an embedded photonic crystal

Appl. Phys. Lett. 92, 251110 (2008); 10.1063/1.2948851

\section{AIP $\left.\right|_{\text {APL Photonics }}$}

APL Photonics is pleased to announce Benjamin Eggleton as its Editor-in-Chief

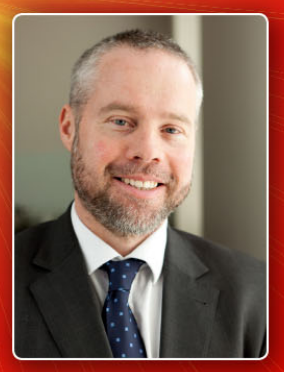




\title{
GaN/InGaN light emitting diodes with embedded photonic crystal obtained by lateral epitaxial overgrowth
}

\author{
Aurélien David, ${ }^{\text {a) }}$ Brendan Moran, Kelly McGroddy, Elison Matioli, Evelyn L. Hu, \\ Steven P. DenBaars, Shuji Nakamura, and Claude Weisbuch ${ }^{\text {b) }}$ \\ Materials Department, University of California, Santa Barbara, California 93106, USA
}

(Received 2 December 2007; accepted 27 February 2008; published online 20 March 2008)

\begin{abstract}
We introduce GaN/InGaN light emitting diodes with a dielectric photonic crystal embedded in the epitaxial layer by lateral epitaxial overgrowth on a patterned GaN template. Overgrowth, coalescence, and epitaxial growth of the pn junction within a thickness of $500 \mathrm{~nm}$ is obtained using metal-organic chemical vapor deposition. This design strongly modifies the distribution of guided modes, as confirmed by angle-resolved measurements. The regime of operation and potential efficiency of such structures are discussed. (C) 2008 American Institute of Physics.

[DOI: 10.1063/1.2898513]
\end{abstract}

In the context of light extraction from nitride light emitting diodes (LEDs), the use of photonic crystals (PhCs) has attracted much attention recently due to their deterministic behavior: they should offer efficient extraction (competitive with a random surface ${ }^{1,2}$ ) and an increased control over the far-field pattern. $^{3-8}$

However, harnessing the full potential of $\mathrm{PhCs}$ has proved difficult: the largest light extraction enhancements reported in the literature are approximately twice, which are largely below theoretical expectations. Indeed, efficient PhCs require full optimization of the design, ${ }^{9}$ including choices of the crystal lattice ${ }^{6}$ and of the vertical structure. ${ }^{7,8}$ In particular, Ref. 5 evidenced that a simple surface $\mathrm{PhC}$ on top of an as-grown structure is of limited efficiency because most of the light is emitted in low-order guided modes which are poorly extracted by the $\mathrm{PhC}$. A possible solution to this issue was introduced in Ref. 8 in which a low-index AlGaN cladding layer modifies the distribution of guided modes. In this case, light emission in the low-order modes of the $\mathrm{GaN}$ buffer is avoided and replaced by strong emission in a mode guided above the cladding layer-the so-called cap layer mode (CLM) - which is efficiently extracted by the PhC. However, growth of the AlN layer is challenging (as for nitride laser diodes), and the PhC still has to be formed in the $p$-GaN, potentially hurting $p$-doping and hindering current injection.

In this letter, we introduce a design which addresses this issue while avoiding the use of a surface $\mathrm{PhC}$ : the $\mathrm{PhC}$ is a patterned dielectric layer embedded in the epitaxial layer by lateral epitaxial overgrowth (LEO), and the active region is located above this layer [Fig. 1(a)]. The dielectric layer acts both as a low-index cladding (whose average index $\langle n\rangle \sim 2$ is lower than that of $\mathrm{AlGaN}$ ) and as a diffracting layer for guided light extraction. The surface of the LED is unpatterned and can be fully used as a contact. Once the epitaxial layer is obtained, regular LED geometries can be employed.

Conventional LEO is employed to obtain lowdislocation GaN (Ref. 10) and makes use of large patterns

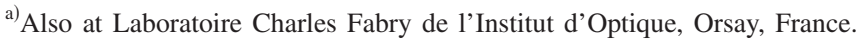
Present address: Philips Lumileds. Electronic mail: aurelien.david@ polytechnique.org.

b) Also at Laboratoire PMC de l'Ecole Polytechnique, Palaiseau, France.
}

(5-50 $\mu \mathrm{m})$. In our case, the $\mathrm{PhC}$ period has to be in the order of $\lambda / n$. The growth thus takes place in a potentially different regime. Besides, for efficient operation of our design, the PhC layer must be thick enough to confine the CLM and coalescence and growth of the $p n$ junction must occur within an optically thin layer. This is illustrated in Fig. 1: a thick top layer supports many guided modes (some of which interact poorly with the $\mathrm{PhC}$ ), while a thin one supports only one CLM, which is efficiently extracted. Due to the low average index in the $\mathrm{PhC}$ layer, $\sim 50 \%$ of the light can be emitted in this CLM, according to solid angle considerations.

Figure 2 indicates the computed extraction efficiencies of the CLM (defined as the imaginary part $k^{\prime \prime}$ of the CLM's wavevector) for various thicknesses of the $\mathrm{PhC}$ layer and of the top layer. A large $k^{\prime \prime}$ is necessary both because light must be extracted over the scale of the LED and because extraction has to compete with absorption mechanisms. In practice, a value of $k^{\prime \prime}=10^{-3} a^{-1}$ corresponds to an exponential extraction length $L_{\text {decay }}=1 / 2 k^{\prime \prime} \sim 100 \mu \mathrm{m}$, which is a reasonable value for a LED. As seen on Fig. $2, k^{\prime \prime}$ strongly varies with the thickness of the top layer. It should ideally be $\sim 350-400 \mathrm{~nm}$ thick to ensure that $k^{\prime \prime}>10^{-3}$. This is challenging since the $p n$ junction itself [including the $n$-doped region, the multiquantum well (MQW), and the $p$-doped re-

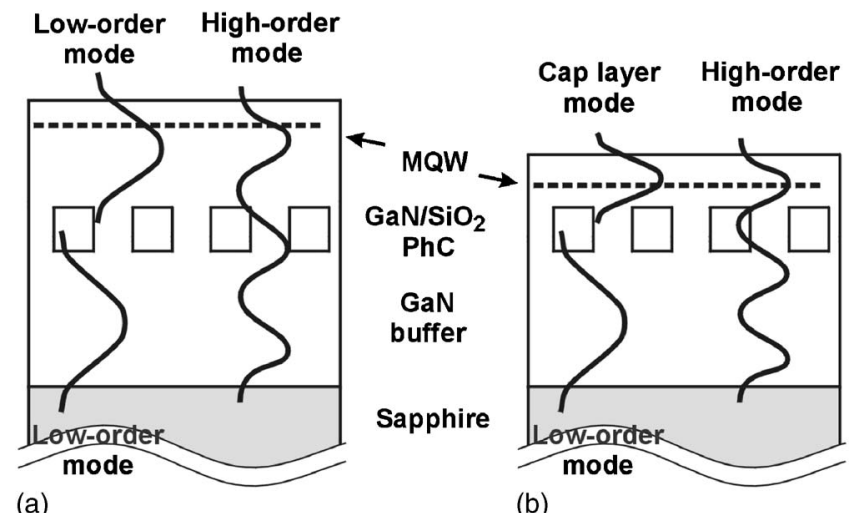

FIG. 1. Structures with an embedded $\mathrm{GaN} / \mathrm{SiO}_{2} \mathrm{PhC}$ and (a) thick and (b) thin top layers above the PhC. (a) Low-order modes (with poor extraction efficiency) are supported both above and below the $\mathrm{PhC}$, in addition to high-order delocalized modes. (b) If the top layer is thin enough, it supports only one strongly confined CLM, which interacts efficiently with the PhC. 


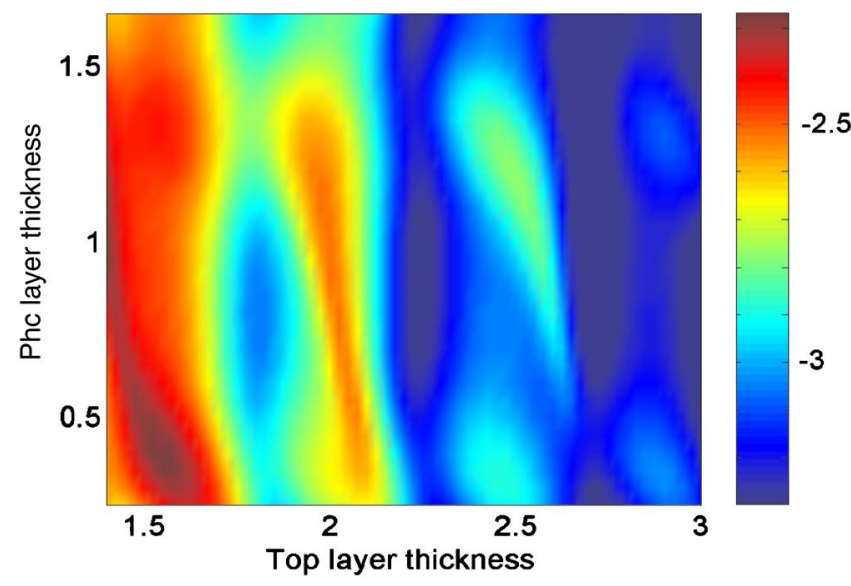

FIG. 2. (Color online) Extraction efficiency $k^{\prime \prime}$ (in units of $a^{-1}, \log _{10}$ scale) of the CLM vs thicknesses of the PhC and the top layer (thicknesses in units of the lattice constant $a$ ). The structure in Fig. 1 is considered with the following parameters: 1-D grating made of $\mathrm{SiO}_{2}$ and $\mathrm{GaN}$ with a period $a$ $=210 \mathrm{~nm}$ and a filling factor $f=0.5$, wavelength $\lambda=450 \mathrm{~nm}$, and the propagation perpendicular to the grating groves.

gion] is typically $300 \mathrm{~nm}$ thick. The demands on the coalescence are thus stringent. Let us also stress that the present calculation considers a one-dimensional (1D) grating. When a two-dimensional (2D) $\mathrm{PhC}$ is considered, $k^{\prime \prime}$ is roughly divided by 3 (intuitively, the diffraction strength of the grating is "spread" over the three $\Gamma M$ directions), requiring a slightly thinner top layer for the same efficiency. Interestingly, we also note that $k^{\prime \prime}$ oscillates with the thicknesses of the $\mathrm{PhC}$ and top layer (due to vertical resonances in both layers). It is thus possible to optimize extraction by finetuning these values.

Let us mention that the use of an embedded grating has already been considered in the past in the context of distributed feedback GaN-based lasers. ${ }^{11}$ However, the design rules for a LED are very different since we operate in a multimode rather than a monomode regime.

The structures are grown as follows: Starting from a GaN template on sapphire, $50 \mathrm{~nm}$ of $\mathrm{SiO}_{2}$ is deposited and patterned by interference holography and dry etching. Care is taken to fully clear the apertures in the mask. In a single metal-organic chemical vapor deposition run, $\mathrm{GaN}$ is then overgrown and coalesced over the stripes and followed by a $p n$ junction containing a MQW active region. Here, we demonstrate the approach on a 1D grating (period $a=210 \mathrm{~nm}$, filling factor $f \sim 0.5$ ), in which coalescence of the LEO is more straightforward, although a 2D grating would improve light extraction. For the coalescence, $\mathrm{GaN}$ is grown at a pressure of 76 Torr, a temperature of $1040^{\circ} \mathrm{C}$, and a V/III ratio of 3900. Two samples were grown for comparison. On the first one, a thick $(\sim 1 \mu \mathrm{m})$ coalescence layer was grown, followed by the LED. On the second one, we obtained full coalescence within only $120 \mathrm{~nm}$ above the $\mathrm{PhC}$ regioncorresponding to a lateral to vertical growth ratio of at least 1 . In this structure, $n$-GaN, the MQW region (emitting at $\lambda$ $=460 \mathrm{~nm}$ ), and $p$-GaN have thicknesses of 200, 60, and $100 \mathrm{~nm}$, respectively. The total thickness of the top layer is thus $\sim 500 \mathrm{~nm}$, which is close to the requirements of Fig. 2 . Figure 3 shows a scanning electron microscope cross section of this structure.

To analyze the optical properties of the $\mathrm{PhC}$, we resort to angle-resolved measurements: the far field of the LED is

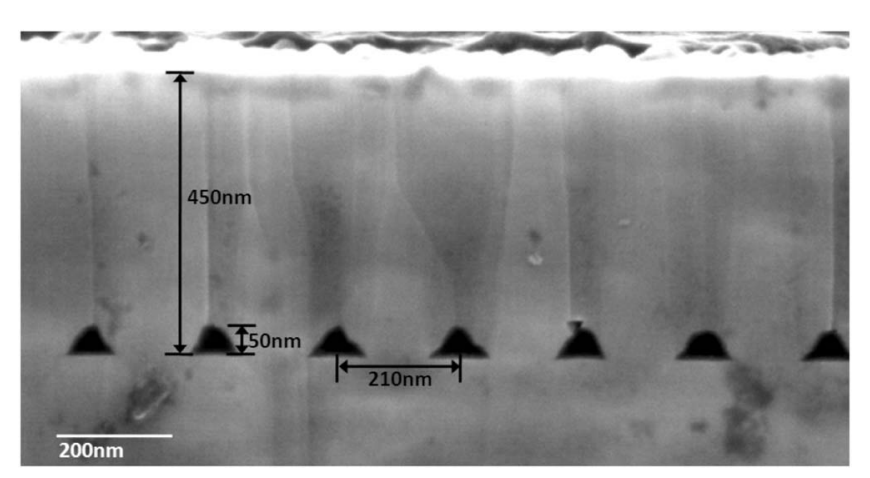

FIG. 3. Scanning electron microscope cross section of the device.

measured as a function of emission angle (from $-90^{\circ}$ to $90^{\circ}$ ). The angle-resolved pattern is then converted into the band structure of the $\mathrm{PhC}$ above the light line, as described in Ref. 5 (in brief, angles and wavelengths are converted to wavevectors $k_{\|}$and reduced frequencies $u=a / \lambda$ ). Figure 4 displays the angle-resolved pattern for the thick and the thin
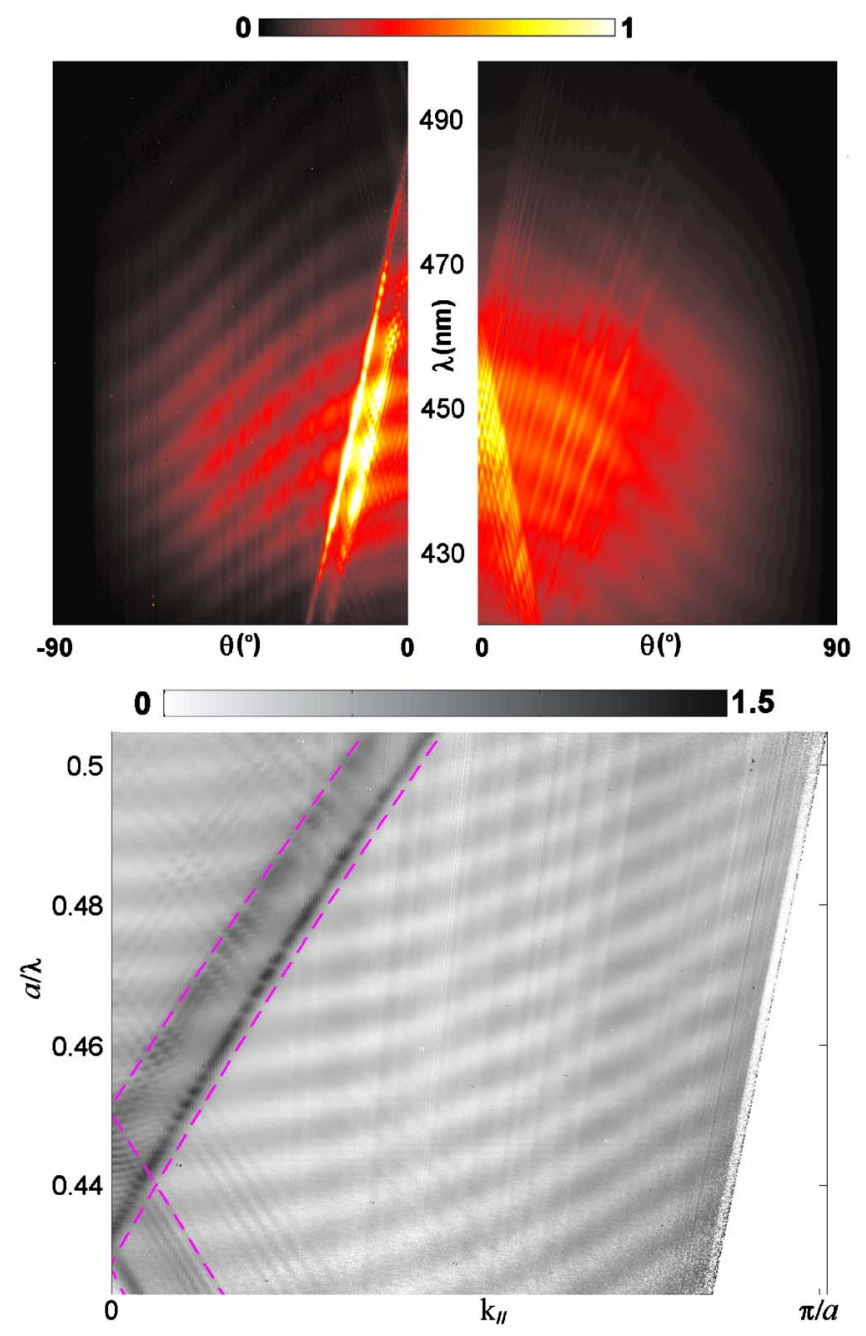

FIG. 4. (Color online) (top) Angle-resolved measurement on the fabricated devices (measured in TE polarization, perpendicular to the grating's groves). In addition to the direct emission of the MQW, a series of sharp lines corresponding to the extracted guided modes appears. Left: Thin device, with two modes dominating the spectrum. Right: Thick device, with multiple guided modes appearing. Intensities are in linear scale. (Bottom) Corresponding band structure (in log scale) for the thin device. The guided modes now anpear as lines, with two intense lines corresponding to the two CLMs. Dashed lines: Fit of these CLMs. 
LEDs and the band structure for the thin LED. For both devices, the pattern is composed of two features: direct light emission into air [the broad continuum in Fig. 4(a), which is modulated by the Fabry-Pérot fringes of the GaN layer] and a series of sharp lines, which are the leaky $\mathrm{PhC}$ modes (i.e., guided modes which are diffracted to air by the $\mathrm{PhC}$ ). Note that the choice of $a=210 \mathrm{~nm}$ diffracts the guided light around normal incidence, thus enhancing the directionality of the LED.

For the thick device, many leaky modes can be observed: these correspond to the multiple high-order modes, which are delocalized across the vertical structure. These modes overlap with the $\mathrm{PhC}$ region and are thus well extracted. For the thin device, one very intense line dominates the spectrum: this is the CLM localized above the $\mathrm{PhC}$ region, which receives a macroscopic fraction of the emitted light and is efficiently extracted. Actually, a second similarbut less sharp-resonance can be observed. Because the top layer is $500 \mathrm{~nm}$ thick, it supports a second optical CLM resonance, but this one is less confined and couples to the multiple modes of the substrate (as manifested by anticrossings). Although an ideal structure would support only one CLM, it turns out that the second CLM is extracted well enough here.

The dispersion of these two CLMs can be fitted by imposing that their vertical wavevectors obey the resonance condition $k_{z}=p \pi / L$, where $L$ is the thickness of the cavity formed by the top layer and $p$ is an integer ( $p=1$ and 2 for the first and second CLMs, respectively). The CLM's dispersion can then be written as $k_{\|}=2 \pi \sqrt{n^{2}-(p \lambda / 2 L)^{2}} / \lambda$. This dispersion is superimposed on Fig. 4: it fits the measurement with good accuracy. The slight discrepancy may be attributed to inaccuracy in the thickness of the top layer (we used the nominal value $L=500$ ) and to an imperfect knowledge of the refractive index $n(\lambda)$ (taken from Ref. 12).

Figure 5 displays the electrical characteristics (voltage and output power versus current) of both samples. The output power was measured on wafer with a photodetector, which was placed above the samples with a collection angle of $\sim 50^{\circ}$. Both devices display some leakage-more notably in the thinner sample, suggesting further optimization of the layer structure. Of note, however, is that the output power is twice larger for the thinner device, which we attribute to a more efficient light extraction. In terms of absolute power, the performance of these structures is low compared to those of regular LEDs. It is unclear whether this is due to the unoptimized growth conditions used for the LEDs on the LEO mask or to some potential detrimental effect of the mask itself (potential contamination by oxygen and diffusion of Si acting as an $n$-dopant). No data on these effects are available at this point, and future investigation of these is required.

In conclusion, we have introduced a design of PhC GaNbased LED in which the PhC is integrated in the epitaxial

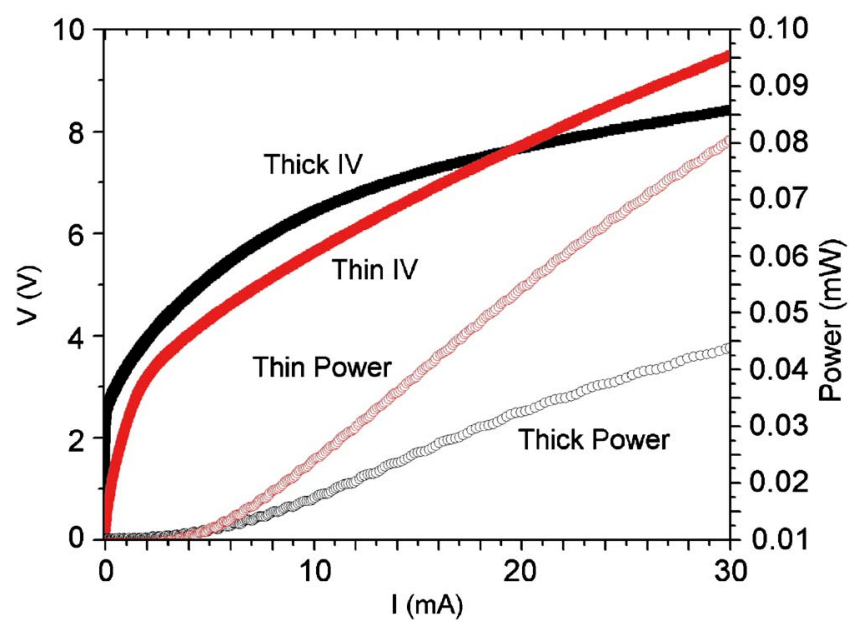

FIG. 5. (Color online) Current-voltage (left scale) and current-power (right scale) characteristics for the thick and the thin samples.

layer and serves as a mask for regrowth of the LED. Overgrowth, coalescence, and growth of the LED were achieved within $500 \mathrm{~nm}$, and the optical properties of the $\mathrm{PhC}$ were characterized. This approach circumvents the limitations of surface $\mathrm{PhCs}$ and, pending optimization and generalization to $2 \mathrm{D}$ coalescence, is a promising candidate for a high brightness InGaN LED.

This work was supported in part by the SSLDC at UCSB and the DOE.

${ }^{1}$ T. Fujii, Y. Gao, R. Sharma, E. L. Hu, S. P. DenBaars, and S. Nakamura, Appl. Phys. Lett. 84, 855 (2004).

${ }^{2}$ O. B. Shchekin, J. E. Epler, T. A. Trottier, T. Margalith, D. A. Steigerwald, M. O. Holcomb, P. S. Martin, and M. R. Krames, Appl. Phys. Lett. 89, 071109 (2006).

${ }^{3}$ J. J. Wierer, M. R. Krames, J. E. Epler, N. F. Gardner, M. G. Craford, J. R. Wendt, J. A. Simmons, and M. M. Sigalas, Appl. Phys. Lett. 84, 3885 (2004).

${ }^{4}$ D. H. Kim, C. O. Cho, Y. G. Roh, H. Jeon, Y. S. Park, J. Cho, J. S. Im, C. Sone, Y. Park, W. J. Choi, and Q. H. Park, Appl. Phys. Lett. 87, 203508 (2005).

${ }^{5}$ A. David, C. Meier, R. Sharma, F. S. Diana, S. P. DenBaars, E. Hu, S. Nakamura, C. Weisbuch, and H. Benisty, Appl. Phys. Lett. 87, 101107 (2005).

${ }^{6}$ A. David, T. Fujii, E. Matioli, R. Sharma, S. Nakamura, S. P. DenBaars, C. Weisbuch, and H. Benisty, Appl. Phys. Lett. 88, 073510 (2006).

${ }^{7}$ A. David, T. Fujii, B. Moran, S. Nakamura, S. P. DenBaars, C. Weisbuch, and H. Benisty, Appl. Phys. Lett. 88, 133514 (2006).

${ }^{8}$ A. David, T. Fujii, R. Sharma, K. McGroddy, S. Nakamura, S. P. DenBaars, E. L. Hu, C. Weisbuch, and H. Benisty, Appl. Phys. Lett. 88, 061124 (2006)

${ }^{9}$ A. David, H. Benisty, and C. Weisbuch, J. Disp. Technol. 3, 133 (2007).

${ }^{10}$ P. Gibart, Rep. Prog. Phys. 67, 667 (2004).

${ }^{11}$ A. C. Abare, M. Hansen, J. S. Speck, S. P. DenBaars, and L. A. Coldren, Electron. Lett. 35, 1559 (1999).

${ }^{12}$ J. F. Muth, J. D. Brown, M. A. L. Johnson, Z. H. Yu, R. M. Kolbas, J. W. Cook, and J. F. Schetzina, MRS Internet J. Nitride Semicond. Res. 4, G5.2 (1999). 